\title{
Indicadores de qualidade para sistemas de preparo do solo no transplantio de citros
} \author{
Marcelo Tufaile Cassia', Tiago de Oliveira Tavares' \\ 'Universidade Estadual Paulista, Jaboticabal, SP, Brasil \\ 2Universidade Federal de Viçosa, Viçosa, MG, Brasil \\ *Autor correspondente, e-mail: vidalonofre@gmail.com
}

Diego Onofre Vidal'*, Murilo Aparecido Voltarelli², Rouverson Pereira da Silva'

\section{Resumo}

O preparo do solo para o transplantio das mudas de citros afeta a longevidade, a produtividade, os aspectos fitossanitários e também a qualidade das operações mecanizadas que deverão ser executadas para garantir o futuro manejo da cultura. Neste contexto, objetivou-se avaliar os indicadores de qualidade dos sistemas de preparo do solo para o transplantio de citros, por meio do desempenho da operação e do estudo de tempos e movimentos dos conjuntos mecanizados. O experimento foi conduzido no município de Matão - São Paulo, em delineamento experimental inteiramente casualizado, sendo avaliados dois sistemas mecanizados para o preparo do solo (convencional e conjugado) para o transplantio de mudas de citros, com 66 repetições para cada tratamento. Foram avaliados como indicadores de qualidade a patinagem dos rodados do trator, velocidade dos conjuntos mecanizados e, por fim, a acurácia do receptor GPS. Também foi realizado um estudo de tempos e movimentos das operações, para efetuar o cálculo da eficiência das operações de preparo do solo. Todos os indicadores de qualidade dos conjuntos mecanizados apresentam-se instáveis, influenciando negativamente a qualidade das operações. O sistema de preparo do solo conjugado e a operação de calagem apresentam a menor e a maior velocidade do conjunto trator-equipamento em relação às demais, respectivamente.

Palavras-chave: Citrus sinensis L., cartas de controle, tempos e movimentos, eficiência dos conjuntos mecanizados

\section{Quality indexes for soil preparation during citrus transplantation}

\begin{abstract}
The soil preparation for citrus seedlings planting can affect the longevity, yield, plant health and the quality of the mechanized operations, which must be $\square$ performed to ensure the future crop management. In this context, this study aimed to evaluate the quality indexes of soil tillage systems during citrus transplanting, through the performance of the operation and the study of times and movements of the mechanized sets. The experiment was conducted in the municipality of Matão - São Paulo, Brazil, in a completely randomized design, with two systems for mechanized soil preparation (conventional and conjugate) to transplant the citrus, with 66 replicates for each treatment. Were evaluated as indicators of quality the wheels slip of the tractor, speed of the mechanized sets, the accuracy of the GPS receiver and a study of time and motion operations, to perform the calculation of the efficiency of the tillage operations of tillage was carried out. All quality indexes for the mechanized sets were unstable, which negatively affects the operations quality. The conjugated tilled system and the liming presented the lowest and the highest speed of the tractor-equipment when compared to others, respectively.
\end{abstract}

Keywords: Citrus sinensis L., control charts, time and motion study, efficiency of the mechanized sets. 


\section{Introdução}

A implantação de um pomar pode-se constituir de uma etapa de maior importância econômica devido ao seu alto custo, uma vez que estão envolvidas diversas operações mecanizadas, que vão desde o preparo do solo até a colocação das mudas nas covas de plantio (Oliveira \& Molin, 2011).

No sistema convencional, após o preparo do solo, é realizado o alinhamento manual das fileiras para o transplantio, etapa que demanda a utilização de uma equipe composta por um profissional de agrimensura e cerca de oito a dez funcionários, que estaqueiam a área para o direcionamento do operador do trator com sulcador para a abertura dos sulcos (Oliveira \& Molin, 2011).

O sistema de preparo de solo conjugado consiste em reunir operações que são realizadas de maneira individual no sistema convencional. A junção de várias operações em uma única operação possibilita menor movimentação de máquinas para desempenhar a mesma finalidade, podendo reduzir a compactação do solo e seu custo (Azevedo, 2003).

As informações sobre o desempenho, qualidade da operação e a capacidade de trabalho das máquinas agrícolas são de grande importância no gerenciamento de sistemas mecanizados agrícolas, auxiliando na tomada de decisões. A obtenção de informações sobre o desempenho é normalmente realizada de modo manual, por meio da análise dos tempos e movimentos, consumo de recursos, mão-deobra e tempo (Molin et al., 2006).

Ultimamente muitos autores têm adotado o monitoramento do processo em atividades de semeadura, tratos culturais e colheita, em diversas culturas, com intuito de se verificar a existência de causas não inerentes ao processo e, criar um plano de melhorias visando garantir que a atividade em estudo atinja as características ideais do planejamento proposto pela Unidade produtora, reduzindo ou eliminando causas de variabilidade (Silva \& Voltarelli, 2015; Zerbato et al., 2015; Santinato et al., 2014; Cassia et al., 2013; Voltarelli et al., 2013; Silva et al., 2013a).

Neste sentido, pressupondo-se que a utilização de um equipamento conjugado realize concomitantemente as operações de preparo do solo para o transplantio de citros com maior nível de qualidade, objetivou-se avaliar os indicadores de qualidade dos sistemas de preparo do solo para o transplantio de citros, por meio do desempenho da operação e do estudo de tempos e movimentos dos conjuntos mecanizados.

\section{Material e Métodos}

O experimento foi conduzido na Fazenda Cambuhy Agrícola, localizada no município de Matão, São Paulo, situado nas proximidades das coordenadas geodésicas de $21^{\circ} 38^{\prime} \mathrm{S}$ e $48^{\circ} 31^{\prime} \mathrm{W}$, com altitude média de $590 \mathrm{~m}$ e clima classificado como Aw (clima Tropical, com chuvas de verão), pelo método de Köppen. As avaliações foram realizadas no mês de agosto de 2011 em um talhão de área total de 16,5 ha, pertencente às áreas de renovação dos pomares da fazenda, sendo 8,0 e 8,5 ha para as operações de preparo convencional e conjugado do solo, respectivamente.

O solo da área experimental foi classificado como LATOSSOLO VERMELHOAMARELO Eutroférrico típico (Embrapa, 2013), de textura média, com declividade média de $5 \%$ (relevo suave ondulado), onde foram realizadas as operações de escarificação seguida de gradagem intermediária e leve como preparo do solo antecedendo as operações mecanizadas de sulcação pelo equipamento convencional e conjugado.

A caracterização do teor de água do solo (umidade gravimétrica) foi realizada por meio da coleta de 132 amostras, sendo 66 para cada tratamento (convencional e conjugado), na camada de 0,0 - 0,15 m, conforme a metodologia recomendada por Embrapa (1997).

O sistema de preparo do solo convencional consiste em três operações distintas: abertura de sulco, calagem e fechamento do sulco. Em contra partida, o sistema de preparo do solo denominado de conjugado consiste do agrupamento das três operações em um único equipamento, o que implica na redução de maquinário e de mão de obra empregada. 
Para o sistema de preparo convencional foi utilizado um equipamento de fabricação interna da empresa Cambuhy Agrícola Ltda, adaptado a partir de um sulcador canavieiro com asas, que realiza a abertura do sulco para uma única linha de transplantio. Posteriormente à abertura realizou-se a calagem direcionada dentro do sulco, utilizando-se um distribuidor de calcário da marca Jan, modelo Lancer 5000. O fechamento do sulco foi realizado com o auxílio de um cultivador canavieiro, adaptado para a cultura de citros, constituído de duas caixas de insumos de metal com capacidade para 370 litros cada, e o conjunto de discos de grade de 32 polegadas que realizam o fechamento do sulco, enquanto que o nivelamento é realizado por uma barra de ferro acoplada por meio de correntes na parte traseira do equipamento.

No sistema de preparo conjugado ou tríplice operação foi utilizado um implemento adaptado a partir do chassi de um sulcador canavieiro, sendo constituído por uma barra porta-ferramenta, duas hastes, e uma outra haste com ponteira com asas centralizado entre as duas hastes citadas. Na parte superior da barra porta ferramentas encontram-se três caixas de distribuição de insumos, sendo duas caixas laterais para os adubos minerais e uma caixa central que recebe o calcário a ser aplicado no sulco. Este implemento conta também com mecanismo de fechamento e nivelamento de sulcos idêntico ao descrito para a operação de fechamento do sulco no preparo do solo pelo método convencional.

Para as operações de abertura e fechamento do sulco no sistema de preparo do solo convencional, bem como para o sistema de preparo de solo conjugado, foi utilizado um trator da marca John Deere, modelo 7715 4×2 TDA, com 134 kW (182 cv) de potência no motor, à rotação nominal de $1.950 \mathrm{rpm}$. O trator é equipado com sistema de direcionamento automático John Deere StarFire ITC, modelo GS3 Greenstar 2630, com precisão de $\pm 0,02 \mathrm{~m}$ para ambos os lados da linha de preparo do solo. Para todas as operações descritas acima se utilizou a mesma marcha (2B) e mesma rotação de trabalho do motor (1900 rpm), sendo monitoradas as variáveis de desempenho operacional, acurácia do sistema direcional e velocidade do conjunto mecanizado.

Para operação de distribuição localizada de calcário no sistema de preparo do solo convencional, utilizou-se um trator da marca Massey Ferguson modelo 275 4×2, com $56 \mathrm{~kW}(75 \mathrm{cv})$ de potência no motor, à rotação de $2200 \mathrm{rpm}$. Para a operação de calagem utilizou-se a marcha 1B e rotação de 1700 rpm no motor, sendo para esta operação coletados somente os dados referentes à velocidade de deslocamento. O abastecimento dos insumos (adubo mineral granulado e calcário) nos dois sistemas de preparo do solo foi realizado com o auxilio de um caminhão munck e por meio de um vagão adaptado pela própria empresa, composto por um motor hidráulico e por uma esteira rolante que direciona $O$ insumo até os compartimentos de carga dos equipamentos.

O delineamento experimental utilizado foi o inteiramente casualizado, materializado em uma malha amostral composta de 198 pontos, espaçados entre si de $6 \times 50 \mathrm{~m}$, sendo 66 repetições para cada tratamento, divididas entre os dois sistemas de preparo de solo para o transplantio de citros pelo método convencional (abertura, calagem e fechamento dos sulcos) e conjugado ou tríplice operação.

A patinagem dos rodados traseiros e dianteiros foi determinada nas operações de abertura e fechamento do sulco, nos dois sistemas. Para estes cálculos, utilizou-se a metodologia descrita por Corrêa et al. (1999) em que se utiliza o número conhecido de giros dos rodados, sem e com carga, em uma determinada distância.

A acurácia do receptor GPS para o alinhamento do preparo dosolofoimensuradapor meio do monitor do sistema de direcionamento automático (piloto automático), considerando como erro de alinhamento os valores de desvios apresentados na tela do monitor, alocado dentro da cabine do trator. A velocidade dos conjuntos mecanizados foi mensurada por meio do sensor de roda que transfere as informações para o computador de bordo do trator, sendo estes valores registrados em planilha eletrônica.

Os tempos gastos em cada operação foram calculados, a partir da mensuração 
por meio de um cronômetro digital, sendo posteriormente anotados em uma planilha, na qual foram determinados os tempos total, produtivo, de manobras e de abastecimento (Araldi et al., 2013). Para o sistema convencional a operação de calagem não foi contabilizada nos tempos ficando somados somente os tempos das operações de abertura e fechamento dos sulcos.

Os resultados foram analisados pela análise exploratória (estatística descritiva) e teste de normalidade de Anderson-Darling para se verificar o comportamento do conjunto de dados, e quando necessário realizou-se a transformação dos dados para sua normalização $y=\ln (x)$. Todas as variáveis ou indicadores de qualidade foram transformadas por meio desta função.

Após a transformação dos dados, foi realizada a análise de variância (ANOVA) aplicando-se o teste F de Snedecor, com nível de significância de $1 \%$, para se verificar a existência ou não de diferenças entre os tratamentos para as variáveis analisadas (Ferreira, 2011).

A análise da qualidade do processo de preparo localizado do solo foi realizada por meio do controle estatístico de qualidade, utilizandose como ferramenta as cartas de controle por variáveis, para monitoramento, análise e detecção de potenciais fatores que podem afetar de modo insatisfatório a operação. O modelo de carta de controle utilizado foi (I-MR: Individual - Amplitude Móvel), constituindo-se do LSC (limite superior de controle), LIC (limite inferior de controle), média dos valores individuais e média da amplitude móvel (Montgomery, 2009). Para evitar valores negativos LIC, O mesmo foi considerado como valor nulo (LIC=0, para a carta de valores individuais e $L I C=1$, para a carta de amplitude móvel), uma vez que para as variáveis em estudo os valores negativos não possuem nenhum significado físico (Voltarelli et al., 2013). Ressalta-se que independentemente da suposição de normalidade, as cartas de controle foram confeccionadas (Korzenowski \& Werner, 2012, Voltarelli et al., 2015).

\section{Resultados e Discussão}

No preparo convencional e conjugado a caracterização do teor de água no solo foi de 6,0 e 2,3\%, respectivamente. Pela Tabela 1, podem ser verificados os parâmetros da estatística descritiva para a patinagem dos rodados traseiros e dianteiros para os dois sistemas de preparo de solo (sulcação, correção e adubação) para o futuro transplantio das mudas de citros. Os valores das médias e medianas encontram-se próximos para as variáveis: abertura de sulco (AS), fechamento de sulco (FS) e operação conjugada (CJ) para a patinagem dos rodados dianteiros e traseiros do trator. Porém, a única variável que apresentou distribuição normal de probabilidade foi O FS para os rodados dianteiros, com os valores dos coeficientes de curtose e assimetria próximos de zero, situação esta que reforça a hipótese de normalidade dos dados deferida pelo teste de Anderson-Darling.

Tabela 1. Estatística descritiva e análise de variância para a patinagem dos rodados do trator na operação de preparo do solo para o transplantio de citros.

\begin{tabular}{|c|c|c|c|c|c|c|}
\hline \multirow{3}{*}{ Parâmetro } & \multicolumn{6}{|c|}{ Patinagem (\%) } \\
\hline & \multicolumn{3}{|c|}{ Rodados dianteiros } & \multicolumn{3}{|c|}{ Rodados traseiros } \\
\hline & $\mathrm{AS}^{1}$ & FS & $\mathrm{CJ}$ & AS & $\mathrm{FS}$ & $\mathrm{CJ}$ \\
\hline Média & $7,3 a$ & $5,1 \mathrm{~b}$ & $7,7 \mathrm{a}$ & $4,2 a$ & $2,5 \mathrm{~b}$ & $4,1 \mathrm{a}$ \\
\hline Mediana & 7,2 & 5,0 & 7,4 & 4,1 & 2,1 & 4,2 \\
\hline Desvio padrão & 1,61 & 1,92 & 2,18 & 1,56 & 1,25 & 1,56 \\
\hline Amplitude & 10,4 & 10,7 & 13,8 & 8,5 & 8,1 & 8,5 \\
\hline CV (\%) & 22,10 & 37,88 & 28,42 & 37,48 & 50,73 & 37,56 \\
\hline Cs & 0,72 & 0,63 & 1,88 & 0,59 & 2,13 & 0,55 \\
\hline Ck & 3,99 & 0,91 & 6,90 & 1,07 & 8,22 & 1,09 \\
\hline$A D$ & $1,12^{\mathrm{A}}$ & $0,38^{\mathrm{N}}$ & $1,76^{\mathrm{A}}$ & $0,77^{\mathrm{A}}$ & $1,67^{\mathrm{A}}$ & $0,57^{\mathrm{A}}$ \\
\hline Teste F & & $34,82^{*}$ & & & $32,06^{*}$ & \\
\hline
\end{tabular}

'AS: abertura de sulco; FS: fechamento de sulco; CJ: operação conjugada. "Significativo pelo teste F a 1\% de probabilidade; ns Não Significativo pelo teste F a $1 \%$ de probabilidade. Para cada variável, médias seguidas por mesma letra na linha não diferem entre si pelo teste $\mathrm{F} \mathrm{a} 1 \%$ de probabilidade. CV, Cs e CK: coeficientes de variação, assimetria e curtose, respectivamente; AD: teste de normalidade de Anderson-Darling (A: distribuição não normal; N:distribuição normal de probabilidade). 
Por outro lado, as operações de abertura de sulco e o preparo conjugado apresentaram distribuição não normal para os rodados dianteiros e traseiros, bem como para o FS para o rodado traseiro, podendo ser confirmado pelos elevados valores de amplitude e desvio padrão do conjunto de dados e ainda com valores de coeficientes de variação altos (Warrick \& Nielsen, 1980).

Observa-se também que, os coeficientes de curtose para as operações de abertura de sulco no preparo convencional e no preparo conjugado apresentaram-se com valores elevados e positivos, para ambos os rodados, indicando curvas com distribuições denominadas de platicúrticas. Ainda para as mesmas operações os coeficientes de assimetria foram todos positivos, indicando curvas mais alongadas a direita (com a maior concentração dos pontos a esquerda), sendo também um indicativo da assimetria e da não normalidade deste conjunto de dados (Montgomery, 2009).

Pela análise de variância constata-se que a patinagem, tanto dos rodados dianteiros quanto traseiro do trator, foram menores para as operações de fechamento do sulco, em relação às patinagens dos rodados na abertura de sulco e na operação conjugada. De acordo ASABE
(2006), os valores de patinagem para maior eficiência de tração, encontram-se entre 11 e 13\% para solos mobilizados, porém, para o presente estudo, de maneira geral para estas operações mecanizadas, os valores de patinagem foram menores do que nesta classificação. Tal situação de valores de patinagens dos rodados do trator menores que os índices estabelecidos pela ASABE (2006) podem ser reflexos do dimensionamento incorreto do trator para a operação, sendo este fato associado ao excesso de lastro no trator (líquido e metálico) e, ou, à utilização de um trator superdimensionado para as operações.

Ressalta-se ainda que, para patinagem dos rodados traseiros pode-se observar menores valores de patinagem, para todos os tratamentos, em relação aos rodados dianteiros do trator, ficando abaixo dos índices recomendados pela ASABE (2006), fato este relacionado à menor carga dinâmica sobre o eixo dianteiro, combinado ao avanço do mesmo que auxilia na capacidade do trator se manter alinhado.

A análise dos parâmetros da estatística descritiva (Tabela 2) para a acurácia do receptor GPS verificou-se que as três operações avaliadas (AS, FS, CJ), apresentaram distribuições não normais de probabilidade pelo teste de normalidade Anderson-Darling.

Tabela 2. Estatística descritiva e análise de variância para a acurácia do GPS e velocidade de deslocamento do preparo do solo para o transplantio de citros.

\begin{tabular}{|c|c|c|c|c|c|c|c|}
\hline \multirow{2}{*}{ Parâmetro } & \multicolumn{3}{|c|}{ Acurácia do GPS (cm) } & \multicolumn{4}{|c|}{ Velocidade $\left(\mathrm{Km} \mathrm{h}^{-1}\right)$} \\
\hline & $\mathrm{AS}^{1}$ & FS & CJ & AS & CA & FS & $\mathrm{CJ}$ \\
\hline Média & $4,8 \mathrm{a}$ & $3,4 a$ & $4,7 \mathrm{a}$ & $5,8 \mathrm{~b}$ & $7,7 \mathrm{a}$ & $5,8 \mathrm{~b}$ & $5,7 \mathrm{C}$ \\
\hline Mediana & 4,0 & 3,0 & 3,0 & 5,9 & 7,8 & 5,9 & 6,0 \\
\hline Desvio padrão & 4,18 & 2,56 & 4,42 & 0,27 & 0,62 & 0,17 & 0,44 \\
\hline Amplitude & 20,0 & 11,0 & 18,0 & 1,40 & 2,93 & 1,2 & 1,20 \\
\hline$C \vee(\%)$ & 86,68 & 74,46 & 93,16 & 4,68 & 8,11 & 2,97 & 7,89 \\
\hline Cs & 1,52 & 0,83 & 1,24 & $-2,93$ & $-1,26$ & $-3,78$ & $-0,83$ \\
\hline Ck & 2,81 & 0,18 & 0,95 & 8,92 & 2,29 & 20,52 & $-1,17$ \\
\hline$A D$ & $2,39^{A}$ & $1,64^{\mathrm{A}}$ & $3,04^{\mathrm{A}}$ & $8,57^{\mathrm{A}}$ & $2,60^{\mathrm{A}}$ & $5,50^{\mathrm{A}}$ & $8,74^{\mathrm{A}}$ \\
\hline Teste F & \multicolumn{3}{|c|}{$1,17^{*}$} & \multicolumn{4}{|c|}{$141,06^{*}$} \\
\hline
\end{tabular}

Em todas as operações constataram-se valores elevados de amplitudes e dos desvios padrão e, ainda, dos coeficientes de variação altos segundo a classificação proposta por Warrick \& Nielsen (1980), indicando elevada variabilidade do conjunto de dados ao longo das operações. Por outro lado, os coeficientes de curtose e assimetria apresentaram-se elevados e positivos, indicando distribuições platicúrticas, devido ao maior achatamento destas curvas em relação a normal e o curvas de distribuição mais alongadas a direita (médias maiores que as 
medianas), respectivamente.

Pela análise de variância, constatase que as operações de AS, FS e CJ foram estaticamente iguais quanto à acurácia do piloto automático em relação ao alinhamento do sulco, situação esta que para a operação de abertura dos sulcos (AS) e para o fechamento dos sulcos (FS), vem a ser interessante, pois, pode-se verificar que entre tais operações a acurácia do alinhamento foi à mesma, refletindo na maior qualidade e alocação dos insumos nos sulcos para o posterior transplantio das mudas. Porém, observa-se que a somatória da acurácia das operações subsequentes AS e FS pode comprometer o erro de alinhamento total desta operação, sendo maior em 57\% quando comparada com a acurácia da operação conjugada.

A elevada variabilidade da acurácia do GPS pode estar relacionada à disposição dos terraços construídos na área para a contenção da água e preservação do solo contra erosões. Neste contexto, a passagem do conjunto sobre os terraços (suave) gera uma variabilidade na profundidade de trabalho das hastes subsoladoras do implemento e um possivel deslocamento horizontal do conjunto mecanizado, o que afeta o tempo de correção do direcionamento do trator em relação as coordenadas estabelecidas pelo sistema do piloto automático.

Pela análise da estatística descritiva para a velocidade dos conjuntos mecanizados, verifica-se que todas operações (AS, CA, FS e CJ) apresentaram frequência de distribuição não normal de probabilidade de acordo com o teste de normalidade de Anderson-Darling, podendo este fato ser comprovado pelos elevados coeficientes de curtose positivos para as operações AS, CA e FS e negativo para a operação CJ (Conrad et al., 2013), bem com os elevados valores dos coeficientes de assimetria negativos em virtude da mediana ser maior em relação as médias desta variável (curva de distribuição dos dados mais alongada para a esquerda) (Lien \& Wang, 2012). Pode-se ainda notar, baixos valores da amplitude e dos desvios padrão e, por fim, dos coeficientes de variação (<30\%) (Warrick \& Nielsen, 1980), situações estas que podem refletir na baixa dispersão dos valores deste conjunto de dados, o que vem a ser satisfatório para este indicador de qualidade durante a operação.

A abertura e o fechamento dos sulcos não diferiram entre si, enquanto que seus valores foram inferiores à da operação de calagem e superiores à conjugada. Tal fato pode ser explicado devido à operação mecanizada de calagem não ser uma operação que demanda alta potência do trator (não movimenta ou revolve solo em profundidade estabelecida), sendo, portando, somente tracionada e realizando a distribuição a lanço de calcário.

A Tabela 3 apresenta os valores dos resultados dos tempos e movimentos da operação, sendo constatado que menor tempo total, produtivo e de manobra para a operação conjugada de preparo do solo, enquanto que somente o abastecimento de insumo foi menor para a operação convencional.

Tabela 3. Análise variância para a eficiência dos tempos gastos nas operações do preparo do solo para o transplantio de citros.

\begin{tabular}{ccccc}
\hline \multirow{2}{*}{ Operações } & \multicolumn{4}{c}{ Tempos das operações $(\mathrm{h})$} \\
\cline { 2 - 5 } & Total & Produtivo & Manobra & Abastecimento de insumos \\
\hline Convencional & $4,45 \mathrm{a}$ & $3,41 \mathrm{a}$ & $0,68 \mathrm{a}$ & $0,36 \mathrm{~b}$ \\
Conjugada & $2,29 \mathrm{~b}$ & $1,17 \mathrm{~b}$ & $0,32 \mathrm{~b}$ & $0,80 \mathrm{a}$ \\
\hline Teste $\mathrm{F}$ & $18,21^{*}$ & $22,14^{*}$ & $19,48^{*}$ & $22,32^{*}$ \\
\hline *significativo pelo teste $\mathrm{Fa}$ a de probabilidade; Não Significativo pelo teste $\mathrm{F}$ a $1 \%$ de probabilidade. Para cada variável, médias seguidas por mesma letra não \\
diferem entre si pelo teste $\mathrm{F}$ a l\% de probabilidade.
\end{tabular}

diferem entre si pelo teste $\mathrm{F}$ a $1 \%$ de probabilidade.

Quando se observam os tempos totais gastos para os dois sistemas de preparo de solo, constata-se que o sistema conjugado apresenta melhor desempenho (menor tempo total), sendo quase duas vezes inferior ao tempo total gasto para o preparo convencional, dobrando a capacidade operacional da operação de preparo do solo para a cultura de citros. Este comportamento se observa também na avaliação dos tempos produtivo e de 
manobra, que foram menores para o preparo conjugado, apresentando valores inferiores a aproximadamente três e duas vezes os tempos consumidos no preparo convencional, respectivamente.

Para o tempo de abastecimento de insumos pode-se observar maior valor de tempo para o sistema conjugado que é aproximadamente duas vezes maior do que o sistema convencional demonstrando que este processo pode ser melhorado. A possível melhoria pode estar associada no melhor planejamento da disposição do caminhão munck, próximo ao conjunto mecanizado, para reabastecer as caixas de adubos em um menor tempo, podendo tornar a operação mais eficiente.

Nas cartas de controle para a patinagem dos rodados dianteiros (Figura la e 1b) observase que, para a operação de abertura e fechamento dos sulcos (preparo convencional) o processo é considerável instável, por haver pelo menos um ponto abaixo (observação $n^{\circ}$ 1) e acima (observação $n^{\circ} 81$ ) dos limites inferior e superior de controle (para as cartas de valores individuais ou de amplitude móvel), respectivamente, podendo estas observações ser consideradas como pontos discrepantes decorrentes da elevada variabilidade da operação, sendo a maior variação verificada para o fechamento dos sulcos (Figura 1b).

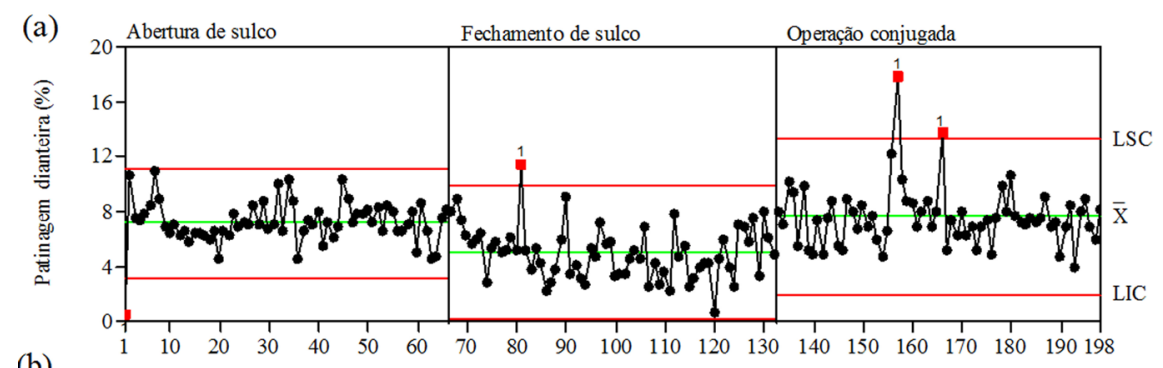

(b)

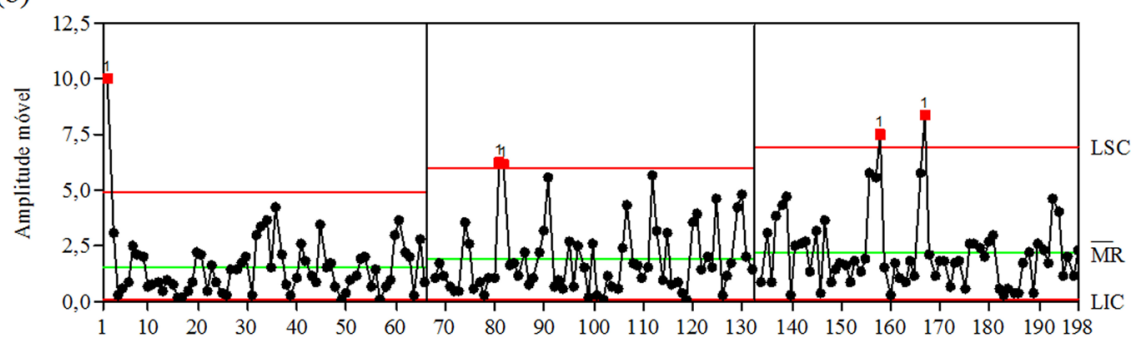

Observações

Figura 1. Cartas de controle para a patinagem dos rodados dianteiro do trator. (a) Carta de valores individuais. (b) Carta de amplitude móvel. LSC: limite superior de controle. LIC: Limite inferior de controle. $X \square$ : média dos valores individuais. $M \square R$ : média da amplitude móvel.

Por outro lado, a operação conjugada também apresentou instabilidade do processo podendo ser verificada na carta de valores individuais (observações no 157 e 166), sendo estes pontos amostrais decorrentes de alguma parte da área na qual houve maior resistência do solo a tração, aumentando, portanto, os índices de patinagem nestes locais. Nota-se também que, em virtude desses elevados valores de patinagem, na carta de valores individuais, os mesmos refletiram também para a instabilidade do processo detectada na carta de amplitude móvel (Figura 2b), sendo para a esta operação a que ocorreu a maior variabilidade do processo (em relação à patinagem da abertura e fechamento dos sulcos).

Para $O$ indicador de qualidade patinagem dos rodados traseiros (Figura 2a), pode-se constatar para o preparo do solo convencional (abertura e fechamento dos sulcos) e conjugado existe a ocorrência de pontos fora dos limites de controle (LSC e LIC) nas cartas de valores individuais e de amplitude móvel, constatando instabilidade do processo, sendo esta associada aos fatores 6 M's (máquinas, mão-de-obra, meio ambiente, matéria-prima, medição e método). Em relação ao que se refere aos $6 \mathrm{M}$ 's, a possível explicação 
pode estar mais relacionada ao meio ambiente, no que se refere a maior resistência do solo a tração para os pontos acima do limite superior de controle e também ao fator máquina, que pode retratar excesso de lastro do trator, com índices geral de patinagem abaixo do recomendado pela ASABE (2006), refletindo em um trator superdimensionado da operação.

Por outro lado, a variabilidade do processo pode ser observada na carta de amplitude móvel (Figura 2b), com destaque para menor variabilidade na operação de fechamento de sulco, em relação ao índice de patinagem dos rodados traseiro, sendo a operação conjugada superior às demais.

Não obstante a instabilidade detectada há que se considerar que foram poucos os pontos fora dos limites de controle, que podem ser atribuídos ao fato de que, no início das operações, bem como nas passagens dos conjuntos sobre os terraços, ocorrem variações nas profundidades de trabalho, fazendo com que haja menor ou maior resistência do solo a tração. Este fato fica mais evidente nas cartas de amplitude móvel que, por representarem a variação do processo, demonstram mais claramente o efeito dessa diferença de resistência à tração quando se compara a diferença de valores individuais ao valor seguinte.

A acurácia do piloto automático, para as operações abertura e fechamento dos sulcos (preparo convencional) e conjugada apresentam-se instáveis, tanto para as cartas de valores individuais como para as de amplitudes móveis (Figura $3 a$ e $3 b$, respectivamente), ou seja, retrata a existência de causas especiais extrínsecas ao processo atuando ao longo da operação.

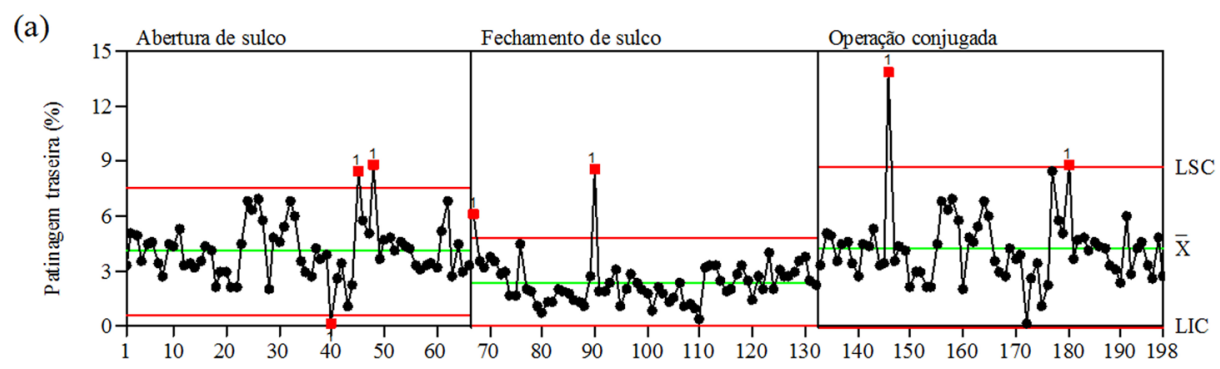

(b)

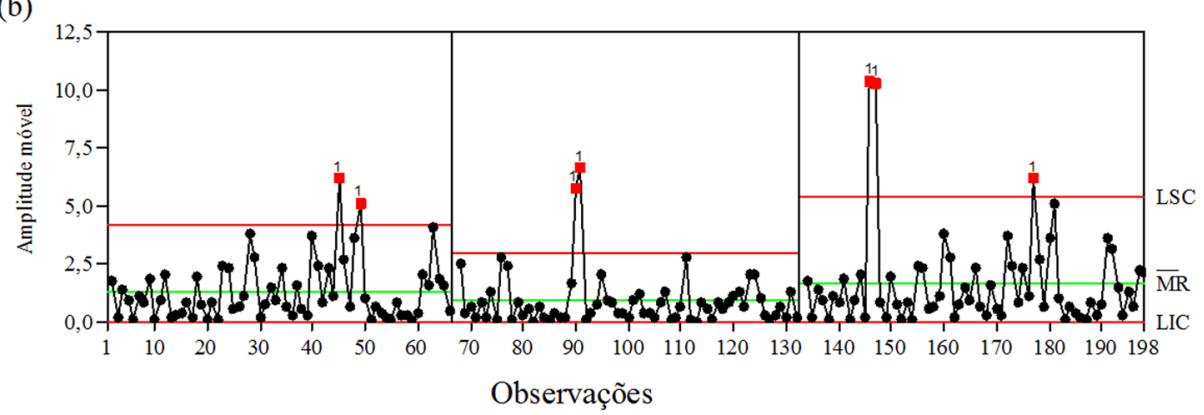

Figura 2. Cartas de controle para a patinagem dos rodados traseiro do trator. (a) Carta de valores individuais. (b) Carta de amplitude móvel. LSC: limite superior de controle. LIC: Limite inferior de controle. $\mathrm{X} \square$ : média dos valores individuais. M $\square$ R: média da amplitude móvel.

Tal instabilidade pode ser explicada devido ao direcionamento das operações, que são realizadas em desnível, obrigando os conjuntos a passar sobre os terraços e nestes locais o conjunto mecanizado sofre deslizamento o que acarreta em maiores valores da acurácia do GPS, perdendo precisão no momento da sulcação. Esses pontos, fora dos limites de controle, são frutos de variações de causas especiais, podendo também ser pontos discrepantes, sendo possível identificar os fatores que causam esta variação para eliminar a instabilidade do processo (Zerbato et al., 2014; Silva et al., 2013a,b; Noronha et al., 2011; Toledo et al., 2008). Entretanto, a eliminação destes pontos não é o objetivo em si deste trabalho, sendo mais importante identificar as possíveis causas da variabilidade, para eliminálas das operações futuras, agregando maior qualidade no decorrer da operação. 


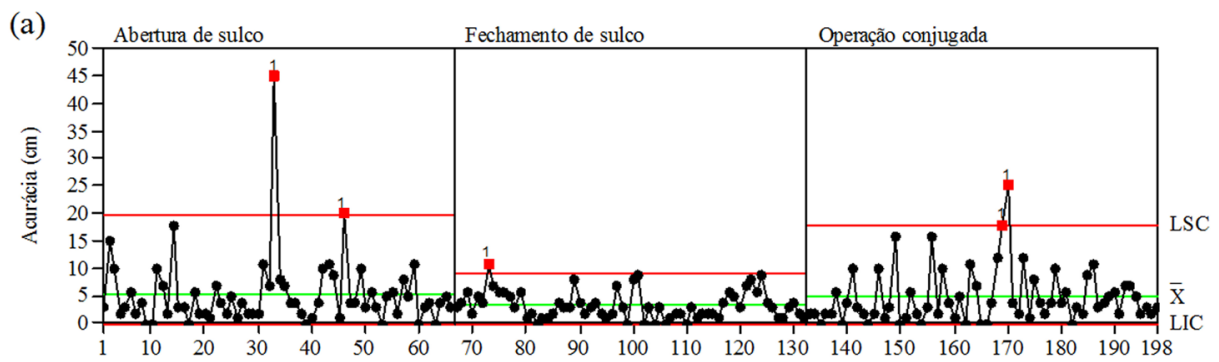

(b)

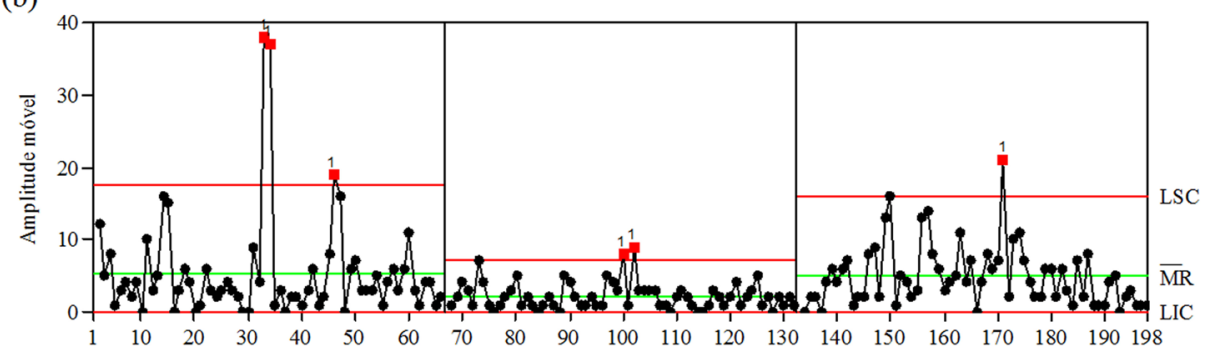

Observações

Figura 3. Cartas de controle para a acurácia do GPS nas operaçōes de preparo do solo para o transplantio de citrus. (a) Carta de valores individuais. (b) Carta de amplitude móvel. LSC: limite superior de controle. LIC: Limite inferior de controle. $X \square$ : média dos valores individuais. M $\square R$ : média da amplitude móvel.

Além disso, outro fato a ser considerado é que, devido à época da realização das operações (mês de agosto), o solo estava com médio teor de água (preparo convencional e conjugado foi de 6,0 e 2,3\%, respectivamente), respectivamente. e também pulverizado em consequência do preparo realizado com escarificador e grades (intermediária e leve), motivos estes que prejudicaram a tração dos rodados, e que juntamente com a massa dos equipamentos, deslocava lateralmente o trator no sentido da declividade do terreno, resultando na oscilação da acurácia do direcionamento automático. Voltarelli et al. (2013) avaliaram o erro de alinhamento do trator, proporcionado de piloto automático, no plantio mecanizado de cana-de-açúcar em um terreno com declividade média de $6 \%$, nos turnos diurnos e noturnos de operação e constataram valores médios semelhantes $(0,0480 \mathrm{~m})$ ao do presente trabalho, bem como também relataram a instabilidade deste processo.

Pela carta de valores individuais do indicador de qualidade velocidade dos conjuntos mecanizados (Figura 4a), nota-se a instabilidade do processo para a operação convencional (abertura e fechamento dos sulcos) e conjugada, tornando-o assim não aleatório, sendo esta explicação demostrada pelos pontos acima ou abaixo dos limites de controle. Observa-se ainda que, a maior variabilidade ocorre para a operação conjugada e a menor para o fechamento dos sulcos, podendo ser verificadas nas cartas de amplitudes móveis (Figura 4b), situação esta que apesar da maior qualidade demostrada para operação de fechamento dos sulcos, não livrou este processo de apresentar-se instável.

As causas especiais destes indicadores de qualidade podem ser derivadas dos fatores máquina e meio ambiente, pois, como mencionado anteriormente, o preparo do solo, bem como as características ponderais dos equipamentos podem ter influenciado no desempenho das operações deste indicador de qualidade. Observa-se que para a operação realizada no sistema conjugado houve grande quantidade de pontos localizados abaixo do limite inferior de controle, indicando a ocorrência de causas especiais, que neste caso podem ser atribuídas ao fator mão de obra, na qual, ou pela fadiga ou desatenção do operador, o mesmo pode ter perdido o controle da velocidade do conjunto mecanizado podendo ser verificado pela elevada quantidade destes menores valores de velocidade fora do limite inferior de controle.

Voltarelli et al. (2015) relataram que a 
carta de valores de individuais é recomendada para o monitoramento de processos agrícolas mecanizados, sendo eficaz para a análise e interpretação dos dados das operações ao longo do tempo, independente da condição de normalidade dos dados, para assim gerenciar melhor os níveis de qualidade desempenhados pelas máquinas e/ou equipamento. Esta situação pode ser semelhante ao que ocorreu para o presente estudo, uma vez que pelo uso das cartas de controle foi detectado eventuais falhas da operação, tornando-se assim necessário a realização um plano de melhorias (Unidade produtora) para aumentar o nível de qualidade das operações futuras.

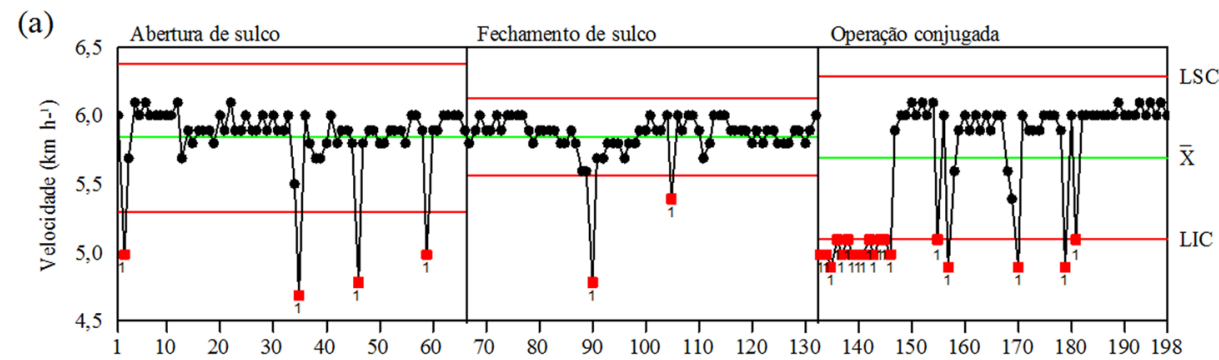

(b)

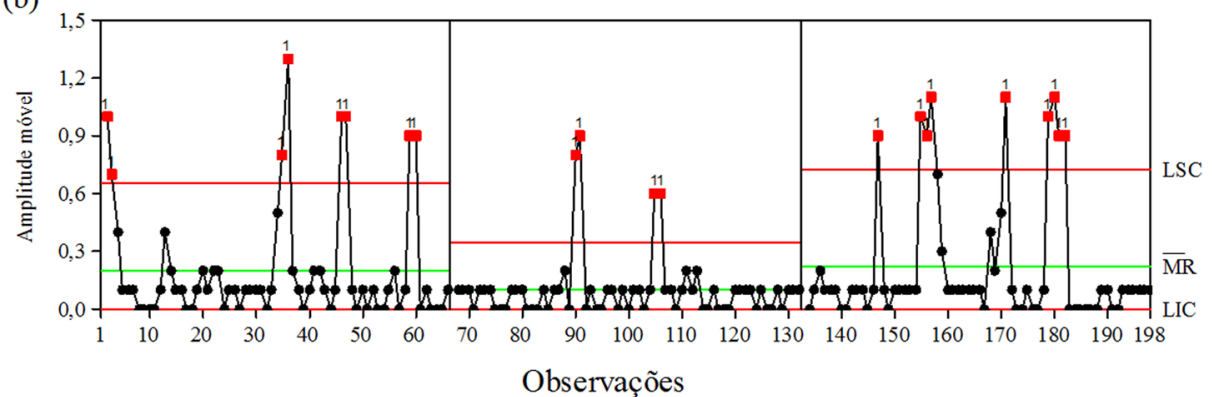

Figura 4. Cartas de controle para a velocidade dos conjuntos mecanizados nas operaçōes de preparo do solo para o transplantio de citrus. (a) Carta de valores individuais. (b) Carta de amplitude móvel. LSC: limite superior de controle. LIC: Limite inferior de controle. $X \square$ : média dos valores individuais. M $\square R$ : média da amplitude móvel.

\section{Conclusões}

Todos os indicadores de qualidade dos conjuntos mecanizados, do método convencional e conjugado de preparo do solo, apresentam instabilidade do processo, influenciando o nível qualidade das operações.

O sistema de preparo do solo conjugado apresenta melhor desempenho operacional, como aproximadamente $50 \%$ a mais de eficiência de tempo.

O sistema de preparo do solo conjugado e a operação de calagem apresentam a menor e a maior velocidade dos conjuntos mecanizados em relação às demais, respectivamente.

\section{Agradecimetos}

Ao CNPa pela bolsa de estudo concedida aos autores e a empresa Cambuhy Agrícola Ltda.

\section{Referências}

ASABE. American Society of Agricultural and Biological Engineers. 2006. In: ASABE EP 496.3. Agricultural machinery management. ASABE, St. Joseph, USA. p. 385-390.

Araldi, P.F., Scholosser, J.F., Frantz, U.G., Ribas, R.L., Santos, P.M. 2013. Eficiência operacional na colheita mecanizada em lavouras de arroz irrigado. Ciência Rural 43: 445-451.

Azevedo, C.L.L. Produção integrada de citros, BA. 2003. http://sistemasdeproducao.cnptia. embrapa.br/FontesHTML/Citros/CitrosBahia/ <Acesso em 20 fev. 2014>

Cassia, M.T., Silva, R.P., Chioderolli, C.A., Noronha, R.H.F., Santos, E.P. 2013. Quality of mechanized coffee harvesting in circular planting system. Ciência Rural 43: 28-34.

Conrad, J., Dittmar, R.F., Ghysels, E. 2013. Ex ante skewness and expected stock returns. The Journal of Finance 68: 85-124.

Corrêa, I.M., Maziero, J.V.G., Yanai, K., Lopes, A. 
1999. Técnicas de determinação de patinagem das rodas motrizes de tratores agrícolas. Instituto Agronômico de Campinas, Campinas, Brasil. 15 p.

EMBRAPA. Empresa Brasileira de Pesquisa Agrícola. 1997. Serviço nacional de levantamento e conservação do solo: Manual de métodos e análise de solo. Embrapa, Rio de Janeiro, Brasil. $212 \mathrm{p}$.

EMBRAPA. Empresa Brasileira de Pesquisa Agropecuária. 2013. Sistema brasileiro de classificação de solos. Embrapa, Brasília, Brasil. 353p.

Ferreira, D.F. 2011 . Sisvar: a computer statistical analysis system. Ciência e Agrotecnologia, 35: 1039-1042.

Korzenowski, A. L., Werner, L. 2012. Probabilidade do erro do tipo I nas cartas X e S de Shewhart sob não normalidade. Produção 22: 807-816.

Lien, D., Wang, Y. 2012. Effects of skewness and kurtosis on production and hedging decisions: a skewed $t$ distribution approach. The European Journal of Finance 1: 1-12.

Molin, J.P., Milan, M., Nesrallah, M.G.T., Castro, C.N., Gimenez, L.M. 2006. Utilização de dados georreferenciados na determinação de parâmetros de desempenho em colheita mecanizada. Engenharia Agrícola 26: 759-767.

Montgomery, D. C. 2009. Introduction to statistical quality control. John Wiley \& Sons, New York, USA $734 \mathrm{p}$.

Noronha, R.H.F., Silva, R.P., Chioderoli, C.A., Santos, E.P., Cassia, M.T. 2011. Controle estatístico aplicado ao processo de colheita mecanizada diurna e noturna de cana-de-açúcar. Bragantia 70: 931-938.

Oliveira, T.C.A., Molin, J.P. 2011. Uso de piloto automático na implantação de pomares de citros. Engenharia Agrícola 31: 334-342.

Santinato, F., Silva, R.P., Cassia, M.T., Santinato, R. 2014. Análise quali-quantitativa da operação de colheita mecanizada de café em duas safras. Coffee Science 9: 495-505.

Silva, R.P., Cassia, M.T., Voltarelli, M.A., Compagnon, A.M., Furlani, C.E.A. 2013a. Qualidade da colheita mecanizada de feijão (Phaseolus vulgaris) em dois sistemas de preparo do solo. Revista Ciência Agronômica 44: 61-69.

Silva, R.P., Voltarelli, M.A., Cassia, M.T., Vidal, D.O., Cavichioli, F.A. 2013b. Qualidade das operações de preparo reduzido do solo e transplantio mecanizado de mudas de café. Coffee Science 9: 51-60.
Silva, R.P., Voltarelli, M.A. 2015. Controle de qualidade em operações agrícolas mecanizadas. Agriworld 6: 44-51.

Toledo, A., Tabile, R.A., Silva, R.P., Furlani, C.E.A., Magalhães, S.C., Costa, B.O. 2008. Caracterização das perdas e distribuição de cobertura vegetal em colheita mecanizada de soja. Engenharia Agrícola 28: 710-719.

Voltarelli, M.A., Silva, R.P., Rosalen, D.L., Zerbato, C., Cassia, M.T. 2013. Quality of performance of the operation of sugarcane mechanized planting in day and night shifts. Australian Journal Crop Science 7:1396-1406.

Voltarelli, M.A., Silva, R.P., Zerbato, C., Paixão, C.S.S., Tavares, T.O. 2015. Monitoring of mechanical sugarcane harvesting through control charts. Engenharia Agrícola 35: 10791092.

Warrick, A. W., Nielsen, D. R. 1980. Spatial variability of soil physical properties in the field. Academic Press, New York, USA 344 p.

Zerbato, C., Furlani, C.E.A., Voltarelli, M.A., Bertonha, R.S., Silva, R.P. 2014. Quality control to seeding systems and densities in peanut crop. Australian Journal of Crop Science 8: 992-998.

Zerbato, C., Furlani, C.E.A., Almeida, R.F., Voltarelli, M.A., Silva, V.F.A. 2015. Quality of peanut mechanical sowing in function of seeding density and size of the seeds. Engenharia Agrícola 35: 711-720. 